\title{
Premorbid cardioselective (but not non-selective) $\beta$ - blocker exposure reduces intensive care unit mortality among septic patients
}

\section{Ming-Jen Kuo}

Taipei Veterans General Hospital

\section{Ruey-Hsing Chou}

Taipei Veterans General Hospital

Ya-Wen Lu

Taipei Veterans General Hospital

Jiun-Yu Guo

Taipei Veterans General Hospital

\section{Yi-Lin Tsai}

Taipei Veterans General Hospital

\section{Cheng-Hsueh Wu}

Taipei Veterans General Hospital

Po-Hsun Huang ( $\nabla$ huangbsvgh@gmail.com )

Taipei Veterans General Hospital

Shing-Jong Lin

Taipei Veterans General Hospital

\section{Research}

Keywords: Sepsis, $\beta$-blocker, cardioselective $\beta$-blocker, tachycardia, catecholamine, intensive care unit

Posted Date: January 7th, 2021

DOl: https://doi.org/10.21203/rs.3.rs-140002/v1

License: (c) (1) This work is licensed under a Creative Commons Attribution 4.0 International License. Read Full License 


\section{Abstract \\ Background}

$\beta$ blockers may protect against catecholaminergic myocardial injury in critically ill patients. Long-term $\beta$ blocker users are known to have lower lactate concentrations and favorable sepsis outcomes. However, the effects of cardioselective and nonselective $\beta$-blockers on sepsis outcomes have not been compared. This study was conducted to investigate the impacts of different $\beta$-blocker classes on the mortality rate in septic patients.

\section{Methods}

We retrospectively screened 2678 patients admitted to the medical or surgical intensive care unit (ICU) between December 2015 and July 2017. Data from patients who met the Sepsis-3 criteria at ICU admission were included in the analysis. Premorbid $\beta$-blocker exposure was defined as the prescription of any $\beta$-blocker for at least 1 month. Bisoprolol, metoprolol, and atenolol were classified as cardioselective $\beta$-blockers, and others were classified as nonselective $\beta$-blockers. All patients were followed for 28 days or until death.

\section{Results}

Among 1262 septic patients, 209 (16.6\%) patients were long-term $\beta$-blocker users. Patients with premorbid $\beta$-blocker exposure had lower heart rates, initial lactate concentrations, and ICU mortality. After adjustment for disease severity, comorbidities, blood pressure, heart rate, and laboratory data, reduced ICU mortality was associated with premorbid cardioselective [adjusted hazard ratio (HR), 0.28; $95 \%$ confidence interval $(\mathrm{Cl}), 0.11-0.74 ; P=0.010]$, but not non-selective (adjusted $\mathrm{HR}, 0.78 ; 95 \% \mathrm{Cl}, 0.30-2.05$; $P=0.611)$, $\beta$-blocker use.

\section{Conclusion}

Premorbid cardioselective, but not non-selective, $\beta$-blocker use was associated with improved mortality in septic patients. This finding supports the protective effect of cardioselective $\beta$-blockers in septic patients. Prospective studies are needed to confirm it.

\section{Introduction}

Sepsis, defined as organ dysfunction caused by a dysregulated host response to infection [1], is a leading cause of death in the intensive care unit (ICU). Despite significant advances in intensive care medicine, septic shock mortality rates remain high, ranging from 40-50\% [1]. Hence, more knowledge of the pathophysiology of sepsis is needed. Overwhelming inflammation, arterial vasodilation, and hypovolemia 
are the main components of the early phase of sepsis. Sympathetic activation is triggered to maintain systemic perfusion and oxygen delivery to vital organs. Adverse effects of catecholamine overactivation in sepsis include tachycardia-induced myocardial damage [2], inflammatory cytokine production [3], insulin resistance [4], and thrombogenicity [5]. Of note, tachycardia occurring with sepsis can increase the cardiac workload and result in myocardial oxygen consumption.

The use of $\beta$-adrenergic blockade is beneficial in patients with diverse cardiovascular diseases. In the recent decades, it has emerged as a possible treatment option in early sepsis to blunt the overwhelming adrenergic responses of cardiogenic [2, 6], metabolic [7], immunological [8], and coagulopathic [5] derangement. In animal models, $\beta$-blocker administration during sepsis appears to reduce the heart rate (HR) and adrenergic activation [9]. In a prospective study, esmolol use permitted the maintenance of target HRs within the range of 80-94 bpm, increased stroke volumes, and improved 28-day survival in septic patients [10]. An observational study revealed that patients with sepsis who had been prescribed $\beta$ blockers before admission had significantly lesser mortality [11]. Other clinical studies also suggest that premorbid $\beta$-blocker exposure has beneficial effects on sepsis outcomes $[12,13]$. However, data on the effects of different types of $\beta$ blocker (cardioselective and non-selective) on sepsis outcomes are scarce. This study was conducted to investigate the impacts of premorbid selective and non-selective $\beta$-blocker use on sepsis outcomes using data from a single medical center. We hypothesized that mortality after sepsis development would be lesser among patients who used $\beta$-blockers, especially cardioselective $\beta$ blockers, in the premorbid period.

\section{Materials And Methods}

\section{Patient selection and data collection}

This retrospective single-center study was conducted with data from patients admitted to the medical or surgical ICU of Taipei Veterans General Hospital, a tertiary medical center, between December 2015 and July 2017. Selected subjects' medical records, including all accessible records of hospitalization, outpatient visits, prescriptions, and examinations, were reviewed. The following data were collected: 1) age, sex, and comorbidities; 2) source of infection and severity of sepsis; and 3) laboratory measurements obtained at the time of ICU admission. Acute Physiology and Chronic Health Evaluation II (APACHE II) scores were calculated within 24 hours after ICU admission to evaluate disease severity [14]. The lowest mean arterial blood pressure (BP) and highest HR within 24 hours after ICU admission were recorded. The study protocol is in accordance with the Helsinki Declaration and international ethical standards, and was approved by the hospital's ethics board (Num. 2017-09-018BC).

We included consecutive patients aged $\geq 18$ years who were admitted to the ICU with the diagnosis of sepsis and fulfilled the Sepsis-3 criteria [1]. We considered patients who had been prescribed $\beta$-blockers for $>1$ month before ICU admission to be premorbid $\beta$-blocker users. We classified $\beta$-blockers as selective (bisoprolol, metoprolol, and atenolol) and non-selective (carvedilol, propranolol, labetalol, and acebutolol) [15]. 


\section{Outcome measurement}

The primary outcome was to evaluate the association between previous $\beta$-blocker prescription and allcause mortality in the ICU. Secondary outcomes were the amount of fluid resuscitation in the first 24 hours of ICU admission, lactate concentrations at 0 and 6 hours after ICU admission, duration of ventilator use, and ICU stay duration. All patients were followed for 28 days or until death.

\section{Statistical analysis}

We express continuous variables as medians \pm standard deviations. Student's $t$ test and analysis of variance were used to compare continuous variables. We express categorical values as absolute numbers with percentages; statistical comparisons were made using the chi-squared test. Cox proportionalhazards regression analysis was performed to investigate independent associations between clinical variables and ICU mortality. Variables with significant associations in the univariable analysis were adjusted for in a final multivariable regression model. To investigate the effects of premorbid $\beta$-blocker use modified by different conditions, we performed subgroup analyses with the cohort stratified by comorbidities and septic shock [1]. The survival curve was plotted using the Kaplan-Meier method with the statistical significance examined by the log-rank test. Two-tailed $P$ values $<0.05$ were considered to be significant. The data were analyzed using IBM SPSS Statistics 23 (SPSS Inc., Chicago, IL, USA) and MedCalc 19.1 (MedCalc Software, Mariakerke, Belgium).

\section{Results}

\section{Study population and baseline characteristics}

Of 2678 cases assessed, 1262 subjects fulfilled the Sepsis-3 criteria. In total, 209 (16.6\%) patients were premorbid $\beta$-blocker users and 1053 patients had no previous $\beta$-blocker exposure. Of the 209 users, 137 patients took cardioselective and 72 patients took non-selective $\beta$-blockers. Supplemental Fig. 1 is a flowchart of patient enrollment and classification. Patient characteristics according to $\beta$-blocker use are presented in Table 1. Hypertension, diabetes mellitus, end-stage renal disease (ESRD), cirrhosis, heart failure, arrhythmia, and coronary artery disease were more prevalent among subjects with premorbid $\beta$ blocker exposure. During initial ICU admission, patients with premorbid exposure to cardioselective $\beta$ blockers had lower HRs than did those with no exposure. Disease severity, reflected by APACHE II scores, did not differ among the three groups. Hypertension and coronary artery disease were more prevalent, and liver cirrhosis was less prevalent, among cardioselective than among non-selective $\beta$-blocker users (Supplemental Table 1). 
Table 1

Baseline characteristic of septic patients grouped by the status of premorbid beta-blocker usage.

\begin{tabular}{|c|c|c|c|c|}
\hline & $\begin{array}{l}\text { Nonusers } \\
(n=1053)\end{array}$ & $\begin{array}{l}\text { Nonselective BB } \\
(n=72)\end{array}$ & $\begin{array}{l}\text { Cardioselective BB } \\
(n=137)\end{array}$ & $P$ value \\
\hline Age & $68.89 \pm 17.30$ & $66.71 \pm 16.73$ & $73.70 \pm 12.88$ & 0.003 \\
\hline Male & $700(66.5 \%)$ & $45(62.5 \%)$ & $94(68.6 \%)$ & 0.673 \\
\hline APACHEII Score & $26.53 \pm 8.46$ & $26.86 \pm 7.72$ & $26.45 \pm 7.33$ & 0.939 \\
\hline \multicolumn{5}{|l|}{ Underlying disease } \\
\hline Hypertension & $474(45.0 \%)$ & $43(59.7 \%)$ & $101(73.7 \%)$ & $<0.001$ \\
\hline DM & $345(32.8 \%)$ & $35(48.6 \%)$ & $63(46.0 \%)$ & $<0.001$ \\
\hline ESRD & $86(8.2 \%)$ & $17(23.6 \%)$ & 19(13.9\%) & $<0.001$ \\
\hline Cirrhosis & $85(8.1 \%)$ & $12(16.7 \%)$ & $7(5.1 \%)$ & 0.014 \\
\hline Heart failure & $98(9.3 \%)$ & 13(18.1\%) & $26(19.0 \%)$ & $<0.001$ \\
\hline Arrythmia & 100(9.5\%) & 11(15.3\%) & $21(15.3 \%)$ & 0.043 \\
\hline CAD & 112(10.6\%) & 13(18.1\%) & $53(38.7 \%)$ & $<0.001$ \\
\hline COPD & $74(7.0 \%)$ & $4(5.6 \%)$ & $9(6.6 \%)$ & 0.881 \\
\hline Cancer (solid tumor) & $308(29.2 \%)$ & $16(22.2 \%)$ & $35(25.5 \%)$ & 0.321 \\
\hline Cancer (hematologic) & $89(8.5 \%)$ & $3(4.2 \%)$ & $4(2.9 \%)$ & 0.038 \\
\hline Autoimmune disease & $58(5.5 \%)$ & $8(11.1 \%)$ & $10(7.3 \%)$ & 0.124 \\
\hline \multicolumn{5}{|l|}{ Infectious source } \\
\hline Pneumonia & $628(59.6 \%)$ & $46(63.9 \%)$ & $91(66.4 \%)$ & 0.262 \\
\hline UTI & 141(13.4\%) & $11(15.3 \%)$ & $23(16.8 \%)$ & 0.522 \\
\hline Blood stream infection & $163(15.5 \%)$ & 11(15.3\%) & $15(10.9 \%)$ & 0.375 \\
\hline$|A|$ & $285(27.1 \%)$ & $18(25.0 \%)$ & $28(20.4 \%)$ & 0.245 \\
\hline Soft tissue infection & $88(8.4 \%)$ & $6(8.3 \%)$ & $10(7.3 \%)$ & 0.914 \\
\hline \multicolumn{5}{|l|}{ Vital signs \& lab data } \\
\hline $\mathrm{HR}$ & $116.40 \pm 23.16$ & $114.89 \pm 25.91$ & $109.52 \pm 22.74$ & 0.005 \\
\hline
\end{tabular}

$\mathrm{BB}, \beta$-blocker; APACHE, acute physiology and chronic health evaluation; DM, diabetes mellitus; ESRD, end stage renal disease; $C A D$, coronary artery disease; $C O P D$, chronic obstruction pulmonary disease; UTI, urinary tract infection; IAl, intra-abdominal infection; HR, heart rate; BP, blood pressure; WBC, white blood cells; CRP, C-reactive protein 


\begin{tabular}{|c|c|c|c|c|}
\hline & $\begin{array}{l}\text { Nonusers } \\
(n=1053)\end{array}$ & $\begin{array}{l}\text { Nonselective BB } \\
(n=72)\end{array}$ & $\begin{array}{l}\text { Cardioselective BB } \\
(n=137)\end{array}$ & $P$ value \\
\hline Mean BP & $61.31 \pm 13.58$ & $67.72 \pm 19.22$ & $62.64 \pm 11.99$ & 0.001 \\
\hline WBC & $12823 \pm 13991$ & $11583 \pm 10380$ & $11628 \pm 6650$ & 0.507 \\
\hline Albumin & $2.79 \pm 0.56$ & $2.93 \pm 0.43$ & $2.91 \pm 0.55$ & 0.060 \\
\hline CRP & $13.46 \pm 10.59$ & $17.24 \pm 12.09$ & $14.34 \pm 8.43$ & 0.161 \\
\hline
\end{tabular}

\section{Premorbid $\beta$-blocker use and clinical outcomes}

Compared with non-users, premorbid cardioselective $\beta$-blocker users had lower ICU mortality and lactate concentrations at 0 and 6 hours after ICU admission. The total amount of fluid infusion, ICU stay, and days of ventilator use did not differ among the three groups (Table 2). In univariate Cox regression analysis, reduced 28 -day mortality was associated with cardioselective, but not non-selective, $\beta$-blocker use [hazard ratio, $0.36 ; 95 \%$ confidence interval $(\mathrm{Cl}), 0.19-0.68 ; P=0.002 ;$ Table 3]. Higher HRs and lower arterial BP also were associated with greater ICU mortality. In the multivariate regression analysis adjusted for age, APACHE II score, hypertension, diabetes, hematological malignancy, HR, mean BP, white blood cell count, and albumin concentration, cardioselective $\beta$-blocker exposure remained associated independently with lesser ICU mortality (adjusted hazard ratio, $0.28 ; 95 \% \mathrm{Cl}, 0.11-0.74 ; P=0.010$ ). A Kaplan-Meier curve also showed that premorbid cardioselective, but not non-selective, $\beta$-blocker exposure was associated with better 28-day survival (log-rank $P=0.002$; Fig. 1 ). 
Table 2

Outcomes of septic patients grouped by the status of premorbid beta-blocker usage.

\begin{tabular}{|lllll|}
\hline & $\begin{array}{l}\text { Non-BB user } \\
(\mathbf{n = 1 0 5 3 )}\end{array}$ & $\begin{array}{l}\text { Non-selective BB user } \\
(\mathbf{n}=72)\end{array}$ & $\begin{array}{l}\text { Selective BB user } \\
(\mathbf{n = 1 3 7 )}\end{array}$ & $P$ value \\
\hline Fluid infusion, $\mathrm{mL} / 24 \mathrm{~h}$ & $5320 \pm 5565$ & $4330 \pm 4077$ & $4333 \pm 4742$ & 0.055 \\
\hline Lactate, 0 h & $25.25 \pm 27.67$ & $18.84 \pm 19.85$ & $18.04 \pm 15.32$ & 0.004 \\
\hline Lactate, 6 h & $24.18 \pm 26.40$ & $19.59 \pm 20.18$ & $16.13 \pm 12.16$ & 0.001 \\
\hline Ventilator days & $13.60 \pm 34.23$ & $13.13 \pm 13.29$ & $14.44 \pm 19.74$ & 0.956 \\
\hline Long term ventilator use & $61(5.8 \%)$ & $4(5.6 \%)$ & $8(5.8 \%)$ & 0.996 \\
\hline Length of ICU stays (days) & $9.82 \pm 6.90$ & $11.29 \pm 8.51$ & $10.81 \pm 7.73$ & 0.087 \\
\hline ICU mortality & $217(20.6 \%)$ & $11(15.3 \%)$ & $13(9.5 \%)$ & 0.005 \\
\hline BB, $\beta$-blocker; ICU, intensive care unit & & & \\
\hline
\end{tabular}


Table 3

Multivariate Cox regression analysis for the usage of beta blockers and incidence of mortality in the intensive care unit.

\begin{tabular}{|c|c|c|c|c|}
\hline & Univariate & & Multivariate* & \\
\hline & Crude HR & $P$ value & Adjusted HR & $P$ value \\
\hline Age & $0.99(0.98-0.99)$ & 0.024 & $0.99(0.98-1.00)$ & 0.178 \\
\hline Male & $0.98(0.72-1.33)$ & 0.887 & & \\
\hline APACHEII & $1.12(1.10-1.15)$ & $<0.001$ & $1.08(1.05-1.11)$ & $<0.001$ \\
\hline Hypertension & $0.66(0.49-0.88)$ & 0.005 & $1.12(0.72-1.74)$ & 0.627 \\
\hline DM & $0.68(0.50-0.93)$ & 0.016 & $0.78(0.50-1.23)$ & 0.285 \\
\hline ESRD & $1.00(0.62-1.63)$ & 0.989 & & \\
\hline Cirrhosis & $1.50(0.93-2.41)$ & 0.095 & & \\
\hline CHF & $1.20(0.77-1.86)$ & 0.429 & & \\
\hline Arrythmia & $0.85(0.52-1.39)$ & 0.512 & & \\
\hline CAD & $0.75(0.48-1.17)$ & 0.206 & & \\
\hline COPD & $0.87(0.48-1.56)$ & 0.634 & & \\
\hline Cancer (solid tumor) & $1.04(0.76-1.43)$ & 0.817 & & \\
\hline Cancer (hematologic) & $4.12(2.68-6.36)$ & $<0.001$ & $2.47(1.27-4.80)$ & 0.008 \\
\hline Autoimmune disease & $1.23(0.70-2.18)$ & 0.474 & & \\
\hline Pneumonia & $0.97(0.74-1.28)$ & 0.848 & & \\
\hline UTI & $0.79(0.51-1.21)$ & 0.273 & & \\
\hline Blood stream infection & $1.26(0.90-1.77)$ & 0.174 & & \\
\hline$|A|$ & $1.13(0.84-1.52)$ & 0.413 & & \\
\hline $\mathrm{HR}$ & $1.02(1.02-1.03)$ & $<0.001$ & $1.01(1.00-1.02)$ & 0.012 \\
\hline Mean BP & $0.96(0.94-0.97)$ & $<0.001$ & $0.98(0.96-0.99)$ & 0.001 \\
\hline WBC & $1.00(1.00-1.00)$ & 0.041 & $1.00(1.00-1.00)$ & 0.221 \\
\hline
\end{tabular}

*Adjusted for variables with $p<0.05$ in the univariate analysis

$\mathrm{HR}$, hazard ratio; APACHE, acute physiology and chronic health evaluation; DM, diabetes mellitus; ESRD, end stage renal disease; $C H F$, chronic heart failure; CAD, coronary artery disease; COPD, chronic obstruction pulmonary disease; UTI, urinary tract infection; IAI, intra-abdominal infection; HR, heart rate; $\mathrm{BP}$, blood pressure; WBC, white blood cells; $\mathrm{CRP}$, c-reactive protein; $\mathrm{BB}$, beta blocker 


\begin{tabular}{|c|c|c|c|c|}
\hline & Univariate & & Multivariate* & \\
\hline Albumin & $0.63(0.46-0.88)$ & 0.006 & $0.73(0.51-1.05)$ & 0.090 \\
\hline CRP & $0.99(0.97-1.02)$ & 0.514 & & \\
\hline BB usage & $0.49(0.31-0.78)$ & 0.003 & & \\
\hline Non-user & Reference & & Reference & \\
\hline Selective BB & $0.36(0.19-0.68)$ & 0.002 & $0.28(0.11-0.74)$ & 0.010 \\
\hline Nonselective BB & $0.75(0.39-1.44)$ & 0.384 & $0.78(0.30-2.05)$ & 0.611 \\
\hline \multicolumn{5}{|c|}{ *Adjusted for variables with $p<0.05$ in the univariate analysis } \\
\hline \multicolumn{5}{|c|}{$\begin{array}{l}\text { HR, hazard ratio; APACHE, acute physiology and chronic health evaluation; DM, diabetes mellitus; } \\
\text { ESRD, end stage renal disease; CHF, chronic heart failure; CAD, coronary artery disease; COPD, chronic } \\
\text { obstruction pulmonary disease; UTI, urinary tract infection; IAI, intra-abdominal infection; HR, heart } \\
\text { rate; BP, blood pressure; WBC, white blood cells; CRP, c-reactive protein; BB, beta blocker }\end{array}$} \\
\hline
\end{tabular}

\section{Subgroup findings}

The results of subgroup analyses are shown in Table 4. Compared with non-use, premorbid cardioselective $\beta$-blocker use was associated with lesser ICU mortality, regardless of the presence or absence of hypertension, diabetes, ESRD, cirrhosis, heart failure, arrhythmia, coronary artery disease, cancer, and septic shock. No significant interaction between any of these variables and cardioselective $\beta$ blocker use was detected. 
Table 4

Subgroup analysis of the relationship between premorbid beta blocker usage and mortality in the intensive care unit.

\section{Selective BB vs. non-usage Peffect Pinteraction \\ Crude OR}

\section{Hypertension}

\begin{tabular}{llll} 
no & $0.46(0.16-1.32)$ & 0.150 & 0.725 \\
\hline yes & $0.36(0.16-0.81)$ & 0.013 & \\
\hline DM & & & \\
\hline no & $0.46(0.22-0.98)$ & 0.043 & 0.408 \\
\hline yes & $0.25(0.08-0.83)$ & 0.024 & \\
\hline ESRD & & & \\
\hline no & $0.44(0.23-0.84)$ & 0.012 & 0.998 \\
\hline yes & & 0.998 & \\
\hline
\end{tabular}

Cirrhosis

$\begin{array}{llll}\text { no } & 0.35(0.18-0.69) & 0.002 & 0.712 \\ \text { yes } & 0.54(0.06-4.77) & 0.581 & \end{array}$

COPD

$\begin{array}{llll}\text { no } & 0.31(0.15-0.61) & 0.001 & 0.073 \\ \text { yes } & 1.64(0.30-8.93) & 0.569 & \end{array}$

$\mathrm{CHF}$

$\begin{array}{llll}\text { no } & 0.38(0.19-0.76) & 0.006 & 0.706 \\ \text { yes } & 0.27(0.06-1.24) & 0.092 & \end{array}$

Arrythmia

$\begin{array}{llll}\text { no } & 0.35(0.17-0.69) & 0.003 & 0.702 \\ \text { yes } & 0.48(0.10-2.25) & 0.351 & \end{array}$

CAD

$\begin{array}{llll}\text { no } & 0.31(0.13-0.73) & 0.007 & 0.475 \\ \text { yes } & 0.51(0.18-1.45) & 0.206 & \end{array}$

$\mathrm{BB}, \beta$-blocker; OR, odds ratio; $\mathrm{DM}$, diabetes mellitus; $\mathrm{ESRD}$, end stage renal disease; $\mathrm{CHF}$, chronic heart failure; CAD, coronary artery disease; COPD, chronic obstruction pulmonary disease 


\section{Selective BB vs. non-usage $\quad P$ effect $P$ interaction \\ Crude OR}

Cancer (solid tumor)

\begin{tabular}{|llll|}
\hline no & $0.40(0.20-0.82)$ & 0.012 & 0.546 \\
\hline yes & $0.25(0.06-1.05)$ & 0.058 & \\
\hline Cancer (hematologic) & & & \\
\hline no & $0.44(0.23-0.84)$ & 0.013 & 0.999 \\
\hline yes & & 0.990 & \\
\hline Septic shock & & & \\
\hline no & $0.33(0.12-0.92)$ & 0.034 & 0.576 \\
\hline yes & $0.48(0.21-1.11)$ & 0.086 & \\
\hline
\end{tabular}

$\mathrm{BB}, \beta$-blocker; OR, odds ratio; $\mathrm{DM}$, diabetes mellitus; $\mathrm{ESRD}$, end stage renal disease; $\mathrm{CHF}$, chronic heart failure; $C A D$, coronary artery disease; $C O P D$, chronic obstruction pulmonary disease

\section{Discussion}

In this retrospective study of data from 1262 septic patients, ICU mortality was lower among patients with premorbid cardioselective $\beta$-blocker exposure. Compared with non-use, premorbid cardioselective and non-selective $\beta$-blocker use was associated with lower lactate concentrations. Only cardioselective $\beta$ blocker use was associated with an improvement in 28-day ICU mortality. This study is the first to illustrate the effects of premorbid exposure to different types of $\beta$ blocker on short-term mortality among septic patients. The findings encourage long-term cardioselective $\beta$-blocker use, but prospective studies are needed to confirm the protective effect of such use in septic patients.

Tachycardia increases the cardiac workload and myocardial oxygen consumption. The shortening of the diastolic filling time during tachycardia decreases the stroke volume and coronary perfusion, contributing to the reduction of the ischemic threshold. Elevated HRs are associated with increased mortality in critically ill patients $[16,17]$, as shown in this study, and a survival benefit of $\beta_{1}$-adrenergic selective blockade has been found in animal models [9]. By decreasing the HR, $\beta$-blockers decrease myocardial oxygen consumption and prolong the diastolic time and coronary perfusion, reducing the risk of myocardial ischemia. Several studies have shown that diastolic dysfunction is present in about half of septic patients and is a significant predictor of mortality [18]. B-blockers have been shown to improve the diastolic function of patients with heart failure [19].

Nevertheless, the treatment of tachycardia during septic shock remains controversial. In the early phase of septic shock, tachycardia compensates for any reduction in cardiac output; HR reduction may interfere with this physiological response, reducing cardiac output and improving oxygen delivery [20]. However, 
tachycardia that persists after adequate resuscitation may represent sympathetic overstimulation. In patients with tachycardia (HR>95 bpm) who received a titrated esmolol infusion with the goal of reducing the HR to 80-94 bpm, decreased HRs were offset by increased ventricular filling time and volume, ultimately resulting in increased stroke volume, which compensated for the HR decrease [10]. Similar hemodynamic effects of $\beta_{1}$-adrenergic selective blockade by esmolol administration have been reported [21, 22]. With adequate preloading, HR reduction improves cardiac performance and efficiency [23], with the maintenance or even increase of the stroke volume. In our study, long-term cardioselective $\beta$ blocker users had significantly lower baseline HRs on ICU admission than did non-selective $\beta$-blocker users; this difference may translate into better outcomes.

Mechanisms other than HR reduction may explain the better sepsis outcomes associated with $\beta$-blocker use. The physiological response to stress includes the increased release of catecholamines. The early phase of sepsis is typically characterized by high cardiac output with decreased vascular tone, tachycardia, and impaired myocardial function. All of these factors can be associated with the elevation of the adrenergic drive to increase global and microvascular blood flow and oxygen delivery to vital organs. The direct cardiotoxic effects of catecholamines, especially norepinephrine, had been recognized for decades. A sustained increase in cardiac adrenergic drive adversely affected myocardial biology and structure phenotype in a heart failure model. The treatment of cardiac myocytes with norepinephrine caused a $60 \%$ loss of these cells [24], and the exposure of cardiac myocytes to isoproterenol had similar effects [25]. Several animal studies have demonstrated the occurrence of $\beta 1$-adrenergic receptor signaling, which is considered to be more harmful to cardiac myocytes than is $\beta 2$-adrenergic receptor signaling $[25,26]$; these findings suggest that $\beta_{1}$-adrenergic receptor signaling is the key mechanism for adrenergic-driven cardiotoxicity. In a clinical trial, differences in $\beta_{1}$-adrenergic and $\beta_{2}$-adrenergic receptor blocking doses indicated that $\beta_{1}$-adrenergic selective blockade had a better treatment effect for heart failure [27]. Hence, chronic $\beta$-blocker (especially cardioselective $\beta_{1}$-blocker) use may protect the heart from the catecholamine surge that occurs during sepsis.

Esmolol also improves microvascular circulation, as determined by assessment of the sublingual microcirculatory blood flow [21]. During sepsis, physiological anticoagulation and fibrinolytic mechanisms are impaired, and the coagulation pathway shifts toward a pro-coagulant state [5]. Coagulation system dysregulation causes the dissemination of intravascular coagulation, leading to microcirculatory dysfunction and tissue production at the cellular level [17]. $\beta_{1}$ - and $\beta_{2}$-adrenergic receptors act differently on coagulation functions. $\beta_{2}$-adrenergic stimulation suppresses platelet aggregation [28]. $\beta_{1}$-adrenergic stimulation inhibits fibrinolysis by reducing prostacyclin synthesis [29], whereas $\beta_{2}$-adrenergic stimulation promotes tissue plasminogen activator release, leading to enhanced fibrinolytic activity. Thus, selective $\beta_{1}$ blockers may reduce platelet activation via relative $\beta_{2}$-adrenergic activation, and enhance fibrinolysis through increased plasminogen activation and prostacyclin synthesis [30]. In the present study, premorbid $\beta$-blocker users had lower baseline lactate levels than did non-users. After initial resuscitation, more premorbid selective than non-selective $\beta$-blocker users achieved $>10 \%$ 
lactate clearance, suggesting that selective $\beta$-blockers improve the pro-coagulation state during sepsis, which plays a role in enhancing microcirculation function.

$\beta_{1}$-and $\beta_{2}$-adrenergic receptors also seem to have different actions on the immune system. Th1 cells stimulate macrophages and natural killer $T$ cells and the production of pro-inflammatory cytokines, whereas Th2 cells have the opposite actions, inhibiting macrophage activation and T-cell proliferation. Th1, but not Th2, cells have $\beta_{2}$-adrenergic receptors. Hence, $\beta_{2}$-receptor stimulation suppresses Th1 cell activation with a relative increase in the Th2 cell response [2]. Thus, selective $\beta_{1}$-blockade could promote $\beta_{2}$-adrenergic pathway activation and contribute to the suppression of the pro-inflammatory status. In septic animal models, esmolol reduced the levels of the pro-inflammatory cytokine tumor necrosis factor (TNF)- $a$ in blood [6] and peritoneal fluid [31]. Metoprolol reduced the hepatic expression of proinflammatory cytokines and the plasma interleukin (IL)-6 level [9]. In contrast, the non-selective $\beta$ blocker propranolol enhanced inflammation and increased the TNF- $\alpha$ and IL-6 levels [32, 33]. The serum levels of anti-inflammatory cytokines, such as IL-10, are increased with stimulation by the selective $\beta_{1^{-}}$ blocker atenolol [8] and by $\beta_{2}$-blockers [34]. Hence, the benefits of $\beta$-blockers may also be immune mediated. Selective $\beta$-blockers have anti-inflammatory effects, which could explain the lower baseline pro-inflammatory cytokine levels and better sepsis outcomes in chronic cardioselective $\beta$-blocker users in this study.

Our findings are in line with previous findings that premorbid $\beta$-blocker exposure is associated with the improvement of outcomes in patients with sepsis [11-13]. Contrary to our findings, Singer et al. [12] reported that the mortality rate was lower among patients with premorbid exposure to non-selective $\beta$ blockers than among those with premorbid cardioselective $\beta$-blocker exposure. However, their study was based on Medicare administrative data, with patient inclusion in 2009-2011 according to ICD-9 diagnostic codes for sepsis, septic shock, and systemic inflammatory response syndrome, without consideration of clinical markers such as laboratory values and vital signs. In the present study, we used the Sepsis-3 criteria for patient inclusion, and considered a broad range of clinical information and data dating to 2015-2017, when sepsis management was more in line with treatment guidelines.

This study has several limitations. First, as it was retrospective, we could not determine the causal relationship between premorbid cardioselective $\beta$-blocker exposure and mortality. Second, it was based on the review of medical records from a single center. Disease severity was greater in our sample than in previous samples; thus, the observed benefits of cardioselective $\beta$-blockers in terms of sepsis outcomes may not extend to all septic patients. Third, the types of $\beta$-blocker prescribed were distributed unevenly; cardioselective $\beta$-blockers are preferred in our region when $\beta$-blocker use is indicated, and non-selective $\beta$ blocker use is predominant for certain diseases, such as liver cirrhosis, which may have caused bias. We attempted to correct for such bias by adjusting the multivariate regression and subgroup analyses for comorbidities. Finally, we only collected the data from the point of ICU admission, which may had been treated partially in the emergency department or ordinary ward. 


\section{Conclusions}

Our findings suggest that premorbid cardioselective, but not non-selective, $\beta$-blocker use is associated with lower ICU mortality among septic patients. The protective effect of cardioselective $\beta$ blockers may be related to their role in the suppression of the overwhelming adrenergic response and their antiinflammatory effects. The results of this study increase our knowledge of the $\beta$-adrenergic activity during sepsis. Prospective studies are needed to confirm the therapeutic potential of cardioselective $\beta$-blocker use in septic patients.

\section{Abbreviations}

APACHE II, acute physiology and chronic health evaluation II; BP, blood pressure; Cl, confidence interval; ESRD, end-stage renal disease; HR, heart rate; ICU, intensive care unit; IL, interleukin; TNF, tumor necrosis factor

\section{Declarations}

\section{Ethics approval and consent to participate}

The Research Ethics Committee of the Taipei Veterans General Hospital approved this study and waived the requirement for informed consent.

\section{Consent for publication}

Not applicable.

\section{Availability of data and materials}

The datasets generated and analyzed are available from the corresponding author on reasonable request.

\section{Competing interests}

The authors declare no competing interests.

\section{Founding}

This study was supported, in part, by research grants from the Ministry of Science and Technology of Taiwan (MOST 106-2314-B-350-001-MY3); the Novel Bioengineering and Technological Approaches to Solve Two Major Health Problems in Taiwan program, sponsored by the Taiwan Ministry of Science and Technology Academic Excellence Program (MOST 108-2633-B-009-001); the Ministry of Health and Welfare (MOHW106-TDU-B-211-113001); and Taipei Veterans General Hospital (V105C-207, V106C-045, V108C-195, V109B-010, V109D50-003-MY3-1). The funding institutions took no part in the study design, data collection or analysis, publication intent, or manuscript preparation. 
Authors' contributions

Research idea and study design: MJ Kuo, RH Chou, PH Huang; data acquisition: MJ Kuo, YW Lu, JY Guo, YL Tsai; data analysis/interpretation: MJ Kuo, RH Chou; statistical analysis: MJ Kuo, RH Chou, CH Wu; supervision or mentorship: PH Huang, SJ Lin. All authors read and approved the final manuscript.

Acknowledgments

None.

\section{References}

1. Singer M, Deutschman CS, Seymour CW, Shankar-Hari M, Annane D, Bauer M, Bellomo R, Bernard GR, Chiche JD, Coopersmith CM et al: The Third International Consensus Definitions for Sepsis and Septic Shock (Sepsis-3). Jama 2016, 315(8):801-810.

2. Suzuki T, Suzuki Y, Okuda J, Kurazumi T, Suhara T, Ueda T, Nagata H, Morisaki H: Sepsis-induced cardiac dysfunction and $\beta$-adrenergic blockade therapy for sepsis. J Intensive Care 2017, 5:22.

3. Elenkov IJ, Wilder RL, Chrousos GP, Vizi ES: The sympathetic nerve-an integrative interface between two supersystems: the brain and the immune system. Pharmacol Rev 2000, 52(4):595-638.

4. Träger $\mathrm{K}$, DeBacker $\mathrm{D}$, Radermacher $\mathrm{P}$ : Metabolic alterations in sepsis and vasoactive drug-related metabolic effects. Curr Opin Crit Care 2003, 9(4):271-278.

5. Schouten M, Wiersinga WJ, Levi M, van der Poll T: Inflammation, endothelium, and coagulation in sepsis. J Leukoc Biol 2008, 83(3):536-545.

6. Suzuki T, Morisaki H, Serita R, Yamamoto M, Kotake Y, Ishizaka A, Takeda J: Infusion of the betaadrenergic blocker esmolol attenuates myocardial dysfunction in septic rats. Crit Care Med 2005, 33(10):2294-2301.

7. Norbury WB, Jeschke MG, Herndon DN: Metabolism modulators in sepsis: propranolol. Crit Care Med 2007, 35(9 Suppl):S616-620.

8. Calzavacca P, Lankadeva YR, Bailey SR, Bailey M, Bellomo R, May CN: Effects of selective $\beta$ 1adrenoceptor blockade on cardiovascular and renal function and circulating cytokines in ovine hyperdynamic sepsis. Crit Care 2014, 18(6):610.

9. Ackland GL, Yao ST, Rudiger A, Dyson A, Stidwill R, Poputnikov D, Singer M, Gourine AV: Cardioprotection, attenuated systemic inflammation, and survival benefit of beta1-adrenoceptor blockade in severe sepsis in rats. Crit Care Med 2010, 38(2):388-394.

10. Morelli A, Ertmer C, Westphal M, Rehberg S, Kampmeier T, Ligges S, Orecchioni A, D'Egidio A, D'Ippoliti F, Raffone $C$ et al: Effect of heart rate control with esmolol on hemodynamic and clinical outcomes in patients with septic shock: a randomized clinical trial. Jama 2013, 310(16):1683-1691.

11. Macchia A, Romero M, Comignani PD, Mariani J, D'Ettorre A, Prini N, Santopinto M, Tognoni G: Previous prescription of $\beta$-blockers is associated with reduced mortality among patients hospitalized 
in intensive care units for sepsis. Crit Care Med 2012, 40(10):2768-2772.

12. Singer KE, Collins CE, Flahive JM, Wyman AS, Ayturk MD, Santry HP: Outpatient beta-blockers and survival from sepsis: Results from a national cohort of Medicare beneficiaries. Am J Surg 2017, 214(4):577-582.

13. Tan K, Harazim M, Tang B, McLean A, Nalos M: The association between premorbid beta blocker exposure and mortality in sepsis-a systematic review. Crit Care 2019, 23(1):298.

14. Knaus WA, Draper EA, Wagner DP, Zimmerman JE: APACHE Il: a severity of disease classification system. Crit Care Med 1985, 13(10):818-829.

15. Bristow MR: beta-adrenergic receptor blockade in chronic heart failure. Circulation 2000, 101(5):558569.

16. Sander O, Welters ID, Foëx P, Sear JW: Impact of prolonged elevated heart rate on incidence of major cardiac events in critically ill patients with a high risk of cardiac complications. Crit Care Med 2005, 33(1):81-88; discussion 241-242.

17. Vellinga NA, Boerma EC, Koopmans M, Donati A, Dubin A, Shapiro NI, Pearse RM, Machado FR, Fries $M$, Akarsu-Ayazoglu T et al: International study on microcirculatory shock occurrence in acutely ill patients. Crit Care Med 2015, 43(1):48-56.

18. Sanfilippo F, Corredor C, Fletcher N, Landesberg G, Benedetto U, Foex P, Cecconi M: Diastolic dysfunction and mortality in septic patients: a systematic review and meta-analysis. Intensive Care Med 2015, 41(6):1004-1013.

19. Bergström A, Andersson B, Edner M, Nylander E, Persson H, Dahlström U: Effect of carvedilol on diastolic function in patients with diastolic heart failure and preserved systolic function. Results of the Swedish Doppler-echocardiographic study (SWEDIC). Eur J Heart Fail 2004, 6(4):453-461.

20. Magder SA: The ups and downs of heart rate. Crit Care Med 2012, 40(1):239-245.

21. Morelli A, Donati A, Ertmer C, Rehberg S, Kampmeier T, Orecchioni A, D'Egidio A, Cecchini V, Landoni G, Pietropaoli P et al: Microvascular effects of heart rate control with esmolol in patients with septic shock: a pilot study. Crit Care Med 2013, 41(9):2162-2168.

22. Balik M, Rulisek J, Leden P, Zakharchenko M, Otahal M, Bartakova H, Korinek J: Concomitant use of beta-1 adrenoreceptor blocker and norepinephrine in patients with septic shock. Wien Klin Wochenschr 2012, 124(15-16):552-556.

23. Morelli A, Singer M, Ranieri VM, D'Egidio A, Mascia L, Orecchioni A, Piscioneri F, Guarracino F, Greco E, Peruzzi $\mathrm{M}$ et al: Heart rate reduction with esmolol is associated with improved arterial elastance in patients with septic shock: a prospective observational study. Intensive Care Med 2016, 42(10):15281534.

24. Mann DL, Kent RL, Parsons B, Cooper Gt: Adrenergic effects on the biology of the adult mammalian cardiocyte. Circulation 1992, 85(2):790-804.

25. Communal C, Singh K, Sawyer DB, Colucci WS: Opposing effects of beta(1)- and beta(2)-adrenergic receptors on cardiac myocyte apoptosis : role of a pertussis toxin-sensitive $\mathrm{G}$ protein. Circulation 1999, 100(22):2210-2212. 
26. Communal C, Colucci WS, Singh K: p38 mitogen-activated protein kinase pathway protects adult rat ventricular myocytes against beta -adrenergic receptor-stimulated apoptosis. Evidence for Gidependent activation. J Biol Chem 2000, 275(25):19395-19400.

27. Bristow MR, Feldman AM, Adams KF, Jr., Goldstein S: Selective versus nonselective beta-blockade for heart failure therapy: are there lessons to be learned from the COMET trial? J Card Fail 2003, 9(6):444-453.

28. Hjemdahl P, Larsson PT, Wallén NH: Effects of stress and beta-blockade on platelet function. Circulation 1991, 84(6 Suppl):Vi44-61.

29. Adler B, Gimbrone MA, Jr., Schafer Al, Handin RI: Prostacyclin and beta-adrenergic catecholamines inhibit arachidonate release and PGI2 synthesis by vascular endothelium. Blood 1981, 58(3):514517.

30. Teger-Nilsson AC, Larsson PT, Hjemdahl P, Olsson G: Fibrinogen and plasminogen activator inhibitor1 levels in hypertension and coronary heart disease. Potential effects of beta-blockade. Circulation 1991, 84(6 Suppl):Vi72-77.

31. Mori K, Morisaki H, Yajima S, Suzuki T, Ishikawa A, Nakamura N, Innami Y, Takeda J: Beta-1 blocker improves survival of septic rats through preservation of gut barrier function. Intensive Care Med 2011, 37(11):1849-1856.

32. Lang CH, Nystrom G, Frost RA: Beta-adrenergic blockade exacerbates sepsis-induced changes in tumor necrosis factor alpha and interleukin- 6 in skeletal muscle and is associated with impaired translation initiation. J Trauma 2008, 64(2):477-486.

33. Schmitz D, Wilsenack K, Lendemanns S, Schedlowski M, Oberbeck R: beta-Adrenergic blockade during systemic inflammation: impact on cellular immune functions and survival in a murine model of sepsis. Resuscitation 2007, 72(2):286-294.

34. Muthu K, Deng J, Gamelli R, Shankar R, Jones SB: Adrenergic modulation of cytokine release in bone marrow progenitor-derived macrophage following polymicrobial sepsis. $J$ Neuroimmuno/ 2005 , 158(1-2):50-57.

\section{Figures}




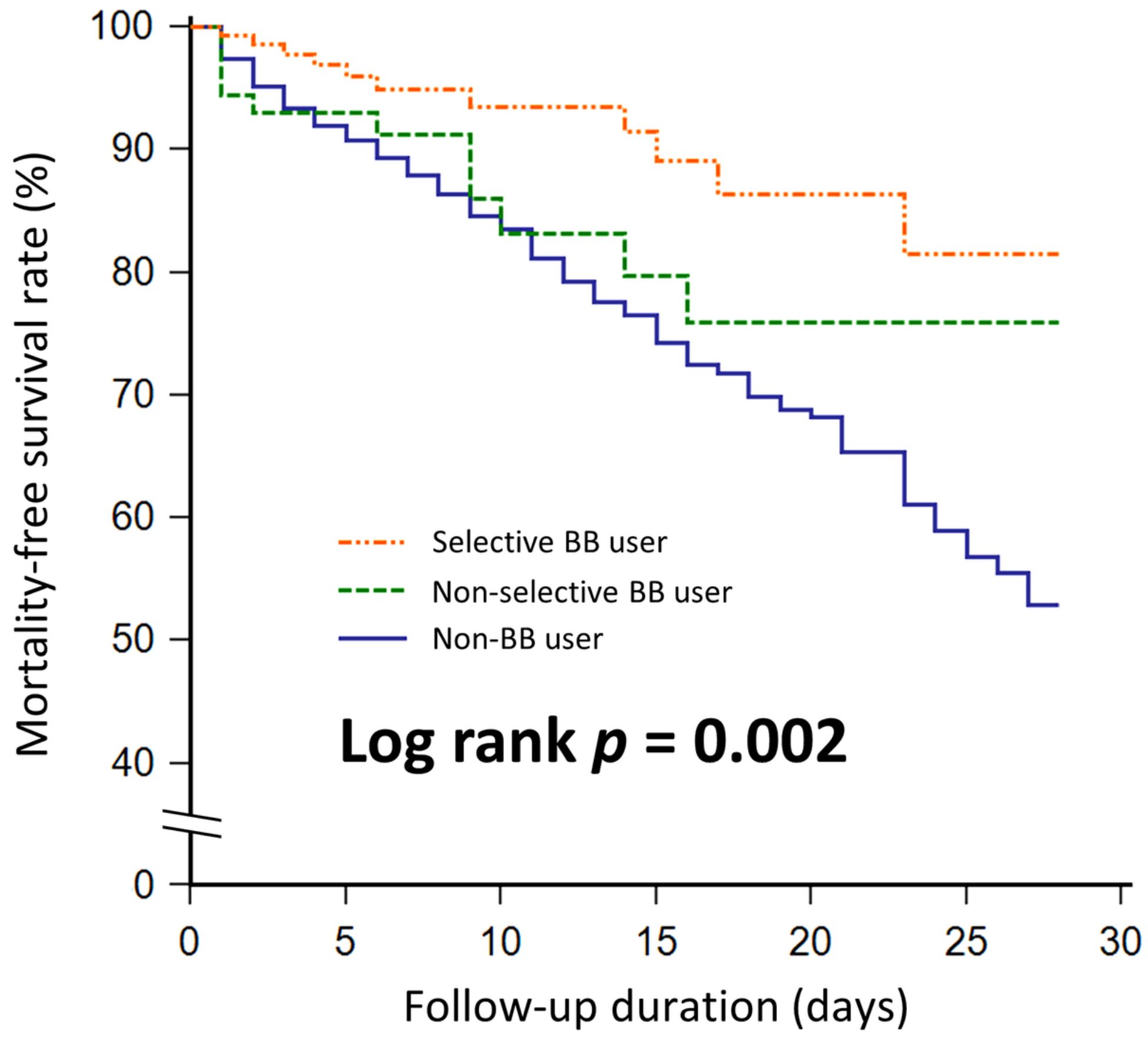

Figure 1

. Kaplan-Meier curves of freedom from 30-days mortality in patients grouped by the status of premorbid beta-blocker (BB) usage.

\section{Supplementary Files}

This is a list of supplementary files associated with this preprint. Click to download.

- SupplementalDigitalContent.doc 